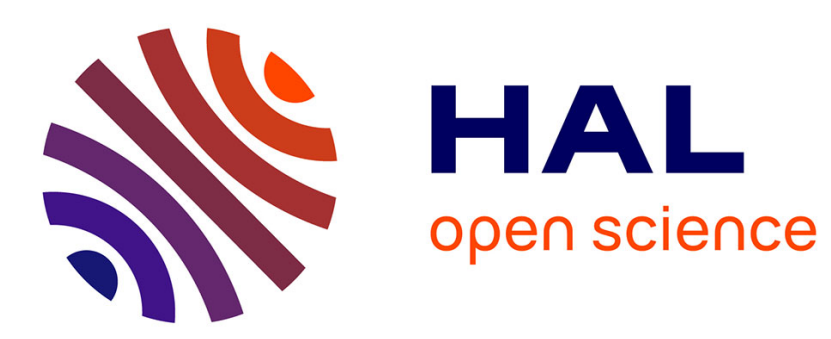

\title{
Improving HIV management in Sub-Saharan Africa: how much palliative care is needed?
}

\author{
Karilyn Collins, Richard Harding
}

\section{To cite this version:}

Karilyn Collins, Richard Harding. Improving HIV management in Sub-Saharan Africa: how much palliative care is needed?. AIDS Care, 2007, 19 (10), pp.1304-1306. 10.1080/09540120701402863 . hal-00513425

\section{HAL Id: hal-00513425 \\ https://hal.science/hal-00513425}

Submitted on 1 Sep 2010

HAL is a multi-disciplinary open access archive for the deposit and dissemination of scientific research documents, whether they are published or not. The documents may come from teaching and research institutions in France or abroad, or from public or private research centers.
L'archive ouverte pluridisciplinaire HAL, est destinée au dépôt et à la diffusion de documents scientifiques de niveau recherche, publiés ou non, émanant des établissements d'enseignement et de recherche français ou étrangers, des laboratoires publics ou privés. 

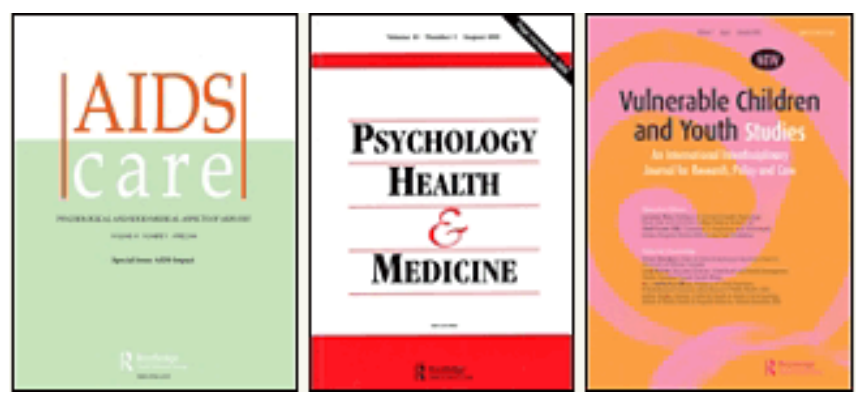

\section{Improving HIV management in Sub-Saharan Africa: how much palliative care is needed?}

\begin{tabular}{|r|l|}
\hline Journal: & $\begin{array}{l}\text { AIDS Care - Psychology, Health \& Medicine - Vulnerable Children } \\
\text { and Youth Studies }\end{array}$ \\
\hline Manuscript ID: & AC-2007-01-0011.R1 \\
\hline Journal Selection: & AIDS Care \\
\hline Keywords: & HIV, Africa, Pain, Palliative, Public Health \\
\hline \multicolumn{2}{|l}{} \\
\hline
\end{tabular}

\section{今 scholarONE \\ Manuscript Central}




\section{Improving HIV management in Sub-Saharan Africa: how much palliative care is needed?}

Word count: 1591

Keywords: HIV, Africa, pain, symptoms, public health, palliative

\section{Abstract}

The WHO advocates palliative care as an essential component of HIV care from the point of diagnosis (when the burden of pain and symptoms may be first experienced) to the end of life and into bereavement (World Health Organisation, 2006). However, in the field of African HIV care, where mortality is high, palliative care has been shown to be largely lacking. This study aimed to measure the prevalence of multidimensional palliative care needs of patients with HIV disease in Muheza, Tanzania.

A prospective census measured presenting problems for all patients during a 1 month period: professional contact; physical symptoms; psychosocial problems; prescribing; and care planning.

During the 4 week period of the study, 731 patients attended for HIV care. The total number of professional contacts was 1512, with 736 nurse, 733 doctor and 43 social worker contacts. Patients were identified as being appropriate for palliative care if they needed pain relief other than simple paracetamol, or if they or their family had complex pain or physical, psychosocial or spiritual needs. 
The mean patient age was 35.4 years $(S D=13.7)$, and 82 patients were under the age of 16 . The majority were female $(70.9 \%)$. Morphine was being prescribed to 21 patients (2.8\%), and ART was being prescribed to 434 (59.4\%). The mean CD4 count was 178.3 cells $\mathrm{mm}^{3}$ (Median=131.1, $\mathrm{SD}=179.9)$.

Palliative care intervention was indicated for 378 (51.7\%) patients. Among those 434 patients using ART, 230 (52.9\%) were indicated as having palliative care needs.

Palliative care continues to be an important part of HIV programmes even in the presence of $A R V$ treatment.

\section{Background}

The WHO defines palliative care as "an approach which improves the quality of life of patients and their families facing life-threatening illness, through the prevention, assessment and treatment of pain and other physical, psychosocial and spiritual problems" (World Health Organisation, 2006). WHO advocates palliative care as an essential component of HIV care from the point of diagnosis to the end of life. This is due to the high prevalence of distressing and apparently refractory pain and other symptoms, both physical and psychological, throughout the disease trajectory.

There are an estimated 25.8 million people living with HIV infection in SubSaharan Africa, with 2.5 million HIV-related deaths during 2006 (UNAIDS, 2006). Although it has been established that palliative care should be 
accessible to all according to need within Africa, coverage is patchy, and evidence in the field of African HIV palliative care largely absent (Harding et. al., 2005). While there are prevalence studies of HIV-related pain and symptoms in resource-rich countries, there is very little from Africa.

Specifically, there have been no studies measuring full-spectrum total care need to informs a public health approach to palliative care provision through Deleted: taking Deleted: a Deleted: approach attention to physical, psychosocial and advanced/terminal care, i.e. the WHODeleted: that

For those providing end-of-life HIV care in Africa, practitioners report a lack of personnel trained in palliative care (Harding et. al., 2003). As African countries move towards a public health approach to palliative care in response to the HIV epidemic, it is essential to have accurate data to inform resource allocation for an adequate clinical response. All care services should be able to provide generalist palliative care within the existing team, with referral/availability of specialist palliative care for complex problems. This study aimed to measure the prevalence of multidimensional palliative care needs of patients with HIV disease attending a care centre in Muheza, Tanzania.

\section{Methods}

Design

This study utilised a prospective 1-month patient census.

Setting 
Teule District Hospital, covers 4922 sq. $\mathrm{km}$ and a population of 300,000 . The HIV prevalence is $10 \%$ of antenatal attendees, and $60 \%$ of medical inpatients. The hospital clinic offers antiretroviral treatment, treatment of opportunistic infections and medical intervention for other problems together with counselling, psycho-social, and spiritual intervention. During 2005, 2077 patients attended for HIV care.

Data collection

A prospective census was undertaken to measure presenting problems for all patients attending at the hospital during a 1 month period in 2005. A data sheet was piloted to capture every professional appointment/consultation between patients and their doctor, nurse or social worker. The variables addressed the most common HIV-related symptoms in Africa, plus psychosocial problems, prescribing and care planning Deleted: contact Deleted: and Deleted: identified from the literature Deleted:

Each patient was allocated a contact record sheet, and firstly demographic (age, gender, place of care) and clinical data (co-morbidities, CD4) were recorded followed by presenting problems and interventions (antiretrovirals, opioids, advanced care planning and terminal care) recorded at each contact.

As this study was undertaken as part of routine practice, the symptoms

(including intensity and site of pain and other symptoms) were discussed with

$\underline{\text { the patient during the clinical appointment, but they were recorded only as }}$

present/absent on the contact record sheet.

Data from each contact were collated at the patient level, and a clinical decision made as to whether the patient was appropriate for palliative care input. Patients were identified as being appropriate for palliative care if the 

patient had an unresolved pain/symptom, and/or patient or family complex
psychosocial/spiritual need.

Analysis

Data were imported into SPSS V12 and descriptive sample characteristics presented. Two regression models were run on the patient level data (with data amalgamated at the patient level for those with multiple professional contacts during the study period), with dependent variables of firstly number of presenting problems (linear regression), and secondly whether palliative care was indicated as appropriate (logistic regression), with age, gender, CD4 count and antiretroviral use as independent variables. Independent variables identified as significant at the $25 \%$ level (Altman, 1991) in univariate analysis were then entered into a multivariate model.

\section{Results}

\section{Patient characteristics}

During the 4 week period 731 patients attended for HIV care. The mean patient age was 35.4 years $(S D=13.7)$, and 82 patients $(11.2 \%)$ were under the age of 16 . The majority were female $(n=507,70.9 \%)$. Morphine was being prescribed to 21 patients (2.8\%), and ART was being prescribed to 434 (59.4\%). The mean CD4 count was 178.3 cells $\mathrm{mm}^{3}$ (Median=131.1, $\mathrm{SD}=179.9$ ), although 518 had CD4 counts of less than $200 \mathrm{~mm}^{3}$, the level at which ART is recommended to be initiated. Of the 518 with CD4 counts below 200, 381 (73.5\%) were currently prescribed ART. 


\section{Presenting problems}

The total number of professional contacts was 1512 , with 736 nurse, 733 doctor and 43 social worker contacts.

Co-morbidities were identified as malignancies (9) not including Kaposi Sarcoma (24), TB (114), PCP (8), toxoplasmosis (3), cardiovascular disease (2), herpes zoster (2), and Cryptococcus (1).

Presenting physical and psychosocial problems, and advanced disease care frequency, are described in Table 1.

\section{Insert Table 1 Here}

Appropriateness for palliative care

The mean number of problems was $2.5(\mathrm{SD}=2.2)$. Palliative care intervention was indicated as appropriate for 378 (51.7\%) patients. Among those 434 patients using ART, 230 (52.9\%) were indicated as having needs appropriate for palliative care.

The multiple linear regression model of number of palliative problems identified the following significant independent variables: $C D 4(b=-0.140$, $p=0.001)$ antiretroviral use $(b=-0.427, p=0.009)$, age and gender were not significant. Palliative care intervention was less likely to be indicated with increasing age $(O R=0.99, p=0.015)$ and $C D 4(O R=0.99, p=0.001)$, gender and ART use were not significant. 


\section{Discussion}

This study presents the first data from Africa describing the prevalence of presenting multidimensional palliative care needs. There are a number of recommendations from the data to inform and plan palliative care provision.

Firstly, the comparatively young population (particularly the 82 patients under the age of 16), highlights the need to provide specialist paediatric palliative care skills in the HIV context. This includes methods to assess children's needs and the clinical skills and formulations for symptom control among children.

Second, although ART is being rolled-out across Africa, $26.5 \%$ of the sample had CD4 count below 200 but were not accessing ART. The access to therapy at this centre is unlimited so this reflects a group of patients either too ill to start $A R V s$, being prepared to start treatment with adherence counselling or those taking treatment for Tuberculosis and awaiting the completion before starting ARVs. Therefore, advanced disease care is still required where unlimited ART access is available.

Third, in answer to the study aim of how much palliative care is needed, $51.7 \%$ of patients had appropriate palliative care needs This level of need should be planned within HIV care services, and may be even higher among those sites with poorer access to ART. However, ART access does not obviate the need for palliative care (Selwyn, 2005), as $52.9 \%$ of those accessing ART in our sample were found to have appropriate palliative care needs. The regression data suggests that while ART use is associated with the number of palliative problems, it is not associated with whether they have 
any such needs or not. As ART is rolled out, services must ensure access to palliative care to enhance the ability to tolerate and adhere to these compounds.

It is important to note that a limitation of this study, i.e. that the methods measured only presenting problems, may result in under-reporting of problems, and increased prevalence. Previous research suggests that physicians detect around $1 / 3$ of HIV patients' clinical problems during consultations (Justice et. al. 2001).

Lastly, our data describe the multidimensional nature of palliative care problems, with difficulties such as social support (23.9\%) and spiritual support (19.4\%) proving the need for a multiprofessional range of palliative-trained staff to be present in the team, as well as for drug availability.

We do not suggest that all of those patients with palliative needs require specialist intervention, but it is essential that staff have basic palliative care training and access to specialist staff for consultancy or co-management for complex cases.

The need for palliative care in a care and treatment programme for HIV starts from diagnosis and continues through treatment to the end of life. Thus, training palliative care needs to be an integral part of training in care and treatment of patients with HIV infection.

Deleted: for 


\section{Reference List}

Altman, D. G. (1991). Practical statistics for medical research. London: Chapmann and Hall.

Harding, R. \& Higginson, I. J. (2005). Palliative care in sub-Saharan Africa. Lancet., 365, 1971-1977.

Harding, R., Stewart, K., Marconi, K., O'Neill, J. F., \& Higginson, I. J. (2003). Current HIV/AIDS end-of-life care in sub-Saharan Africa: a survey of models, services, challenges and priorities. BMC Public Health.3:33, 3.

Justice, A. C., Chang, C. H., Rabeneck, L., \& Zackin, R. (2001). Clinical importance of provider-reported HIV symptoms compared with patient-report. Medical Care., 39, 397-408.

Selwyn, P. A. (2005). Why should we care about palliative care for AIDS in the era of antiretroviral therapy? Sexually Transmitted Infections., 81, 2-3.

UNAIDS (2006). Sub-Saharan Africa. UNAIDS [On-line]. Available: http://www.unaids.org/en/regions countries/regions/subsaharanafrica.esp 
World Health Organisation (2006). Palliative Care. World Health

Organisation [On-line]. Available:

http://www.who.int/hiv/topics/palliative/care/en 
Table 1 - Physical and psychosocial problems and advanced disease care prevalence

\begin{tabular}{|l|l|}
\hline \multicolumn{1}{|c|}{ Physical symptoms } & \multicolumn{1}{c|}{$\mathbf{N}(\%)$} \\
\hline Pain (not neuropathic) & $374(41.4)$ \\
\hline Cough & $235(26)$ \\
\hline Skin problems & $209(23.1)$ \\
\hline Neuropathy & $146(16.2)$ \\
\hline Weakness & $124(13.7)$ \\
\hline Nausea/vomiting & $123(13.6)$ \\
\hline Anorexia & $77(8.5)$ \\
\hline Diarrhoea & $61(6.8)$ \\
\hline Breathlessness & $57(6.3)$ \\
\hline Oedema & $33(3.7)$ \\
\hline Constipation & $20(2.2)$ \\
\hline Agitation/confusion & $9(1)$ \\
\hline Immune reconstitution syndromes & $6(0.7)$ \\
\hline & \\
\hline \multicolumn{1}{|c|}{ Psychosocial problems } & \\
\hline Social support & $216(23.9)$ \\
\hline Spiritual support need & $175(19.4)$ \\
\hline Anxiety/depression & $119(13.2)$ \\
\hline Family worries/concerns & $96(10.6)$ \\
\hline Child care & $80(8.9)$ \\
\hline Hunger & $66(7.3)$ \\
\hline Complex family issues & $38(4.2)$ \\
\hline \multicolumn{1}{|c|}{ Advanced disease care } & \\
\hline Advanced care planning & $18(2)$ \\
\hline Terminal care & $6(0.7)$ \\
\hline
\end{tabular}

